\title{
Efficacy of Natural Zeolite and Metakaolin as Partial Alternatives to Cement in Fresh and Hardened High Strength Concrete
}

\author{
Iswarya Gowram $\mathbb{D}^{1},{ }^{1}$ Beulah $M \mathbb{D}^{1},{ }^{1}$ MR Sudhir $\mathbb{D}$, ${ }^{1}$ Mothi Krishna Mohan $\mathbb{D}{ }^{2}$ \\ and Deekshith Jain $\left.{ }^{3}\right)^{3}$ \\ ${ }^{1}$ Department of Civil Engineering, School of Engineering \& Technology, Christ (Deemed to Be University), \\ Bangalore 560074, Karnataka, India \\ ${ }^{2}$ Department of Science and Humanities, Christ (Deemed to Be University), Bangalore 560074, Karnataka, India \\ ${ }^{3}$ Department of Construction Technology and Management, Bule Hora University, POB 144, Oromia, Ethiopia
}

Correspondence should be addressed to Deekshith Jain; deekshith.jain@bhu.edu.et

Received 15 September 2021; Revised 1 November 2021; Accepted 18 November 2021; Published 3 December 2021

Academic Editor: Kaushik Kumar

Copyright (c) 2021 Iswarya Gowram et al. This is an open access article distributed under the Creative Commons Attribution License, which permits unrestricted use, distribution, and reproduction in any medium, provided the original work is properly cited.

\begin{abstract}
Urbanization and industrialization have dramatically increased the manufacture of cement causing substantial pollution of the environment. The primary global concern related to cement manufacture has been the management of the large carbon footprints. The usages of environmentally friendly cementitious materials in the construction of structures have proved to be a viable option to deal with this environmental concern. Therefore, it is necessary to further explore the usage of cementitious materials which can replace cement albeit partially. In this direction of research, two such cementitious materials, namely, natural zeolite and metakaolin have been investigated in this study. High-strength concrete M60 with natural zeolite and metakaolin as the partial replacements for the cement has been prepared in this work. Polycarboxylic ether-based superplasticizer solution has been used to enhance workability. The test specimen cast and cured for 3, 7, 28, 60, and 90 days at ambient room temperature has been tested for compressive strength, split tensile strength, and flexural strength as per the Indian standards. The optimum mix of highstrength concrete thus manufactured has met the Indian standards, and the combination of cement $+5 \%$ natural zeolite $+10 \%$ metakaolin has exhibited the highest compressive, split tensile, and flexural strengths at 90 days of curing. Natural zeolite and metakaolin when used in smaller proportions have increased the concrete strength, and these materials are recommended for partial replacement of cement.
\end{abstract}

\section{Introduction}

Concrete is one of the most widely used construction materials in the world. Cement, water (active components), fine particles, and coarse aggregates (inactive members) are the fundamental ingredients of concrete $[1,2]$. Cement manufacture produces a significant amount of carbon dioxide. Cement can be partially replaced by pozzolanic materials or industrial wastes to reduce $\mathrm{CO} 2$ emissions [3, 4]. By filling the pores and lowering the porosity and permeability of the concrete without sacrificing the required characteristics, natural zeolite and metakaolin materials improve the durability and strength of the concrete. By fulfilling current and future demands, the notion of sustainability enhances human well-being and quality without compromising it. Due to urbanization, population expansion, and economics, the construction sector directly influences the environment by utilizing cement $[5,6]$. It is necessary to use sustainable building materials or processes to minimize carbon dioxide emission and moderate global warming [7]. Because cement is the primary building material in the construction sector, it is essential to convert to sustainable methods and materials owing to the dangerously increasing demand of cement and its significant environmental effect. Various admixtures have 
been utilized to produce concrete, and therefore the concrete may be made more tolerable by substituting cement components. Natural zeolite is a mineral composed of silicate and aluminate constituents. Metakaolin is a pozzolanic substance that can replace cement in concrete. Both metakaolin and kaolinite are clay minerals that have been dehydroxylated $[8,9]$. The use of these mineral admixtures has attracted much attention in the last two decades especially in the building sector because they are ecologically benign and increase the strength and durability of concrete. The production and successful use of zeolite $[10,11]$ and metakaolin $[12,13]$ have been discussed. The major investigations for hardened concrete are the split tensile strength, compressive strength, water absorption, and modulus of elasticity. The laboratory experiment on high-strength concrete for durability and strength by adding zeolite was carried out by a descriptive-analytical approach [14-16]. The endurance and mechanical characteristics of concrete containing zeolite, metakaolin, and tiny nanobubbles of water have been investigated $[17,18]$. The ELM model was used to investigate the compressive strength of high-strength concrete utilizing 324 data records acquired from laboratory tests. The ELM model has been trained and verified [19].

A study was performed to assess the effects of magnetic water with different percentages of natural zeolite (NZ) on self-compacting concrete (SCC) mixes [20]. Physiochemical characterization of zeolite and appraisal of potential as a pozzolanic material in structural concrete were the subjects of two separate experiments wherein the compression strength of the hardened concrete was also evaluated [21].

A study on concrete using natural zeolite as a partial substitute for regular Portland cement of 53 grade with coarse aggregates of $10-12 \mathrm{~mm}$, fine aggregates, zeolite, and water was carried out. Compressive strength tests were performed on $150 * 150 * 150 \mathrm{~mm}$ cubes for 7,14 , and 28 days [22]. In this study, the physical-mechanical characteristics of zeolite and cement and the chemical and mineral parameters of fine and coarse aggregates were estimated. Compressive strength, density, water absorption, porosity, ultrasonic pulse velocity, and freeze-thaw resistance were tested in the lab. The results revealed that replacing $10 \%$ of the cement with natural zeolite enhanced porosity and later improved freeze-thaw resistance. When $10 \%$ natural zeolite was substituted for $10 \%$ cement in the freeze-thaw resistance calculations, the concrete exhibited 3.3 times greater resistance [23]. Experiments were conducted on concrete incorporating natural zeolite as a cement substitute in blended Portland cement up to $60 \%$ by mass. The basic physical parameters, fracture mechanics properties, mechanical properties, durability qualities, and hydric thermal properties were investigated [24].

An examination of the impact of natural zeolite as an additive to concrete building from the perspective of freeze/thaw resistance was undertaken using computer simulations. The examination covered two types of concrete for hygrothermal behavior: reference concrete without any admixtures and zeolite concrete with 40\% zeolite as cement replacement. The mathematical calculations were effectuated using the computer simulation program HEMOT, and the process input parameters were employed by the FEM [25]. A study was carried out on high-strength concrete using a trial combination designed to achieve goal strength of more than $90 \mathrm{MPa}$ for a control mixture after 28 days of curing and a consistent water/ binder ratio of 0.3 for all the mixes. Four distinct mixes, each with a partial replacement of cement with metakaolin of $0,5,10$, and $15 \%$, were created to test the effect of low water to binder ratio on the mechanical and durability qualities of concrete mixes containing metakaolin [26, 27]. The compressive strength and water absorption of cubes of size $100 \mathrm{~mm}^{*} 100 \mathrm{~mm}^{*} 100 \mathrm{~mm}$ and split tensile test of cylinders of size $100 \mathrm{~mm}^{*} 200 \mathrm{~mm}$, GWT water permeability test, and water penetration tests were conducted on $150 \mathrm{~mm}^{*} 150 \mathrm{~mm}^{*} 150 \mathrm{~mm}$ cubes.[28]. An experimental examination of concrete durability and strength with cement substituted with zeolite $[29,30]$ and metakaolin [31-33] was undertaken.

A study on concrete mixed with metakaolin and concrete mixed with zeolite subjected to compression strength tests for $3,7,28$, and 90 days was conducted. The study used ordinary Portland cement (OPC), metakaolin (MK), silica fumes (SF), and fly ash as binders in concrete (FA). Polymetric naphthalene sulphonate was used as a chemical additive in the concrete $[34,35]$. An examination of the crystallography of the binder components was conducted using XRD analysis. The W/B ratio was determined as 0.5 after 56 days of curing by SEM, EDS, and XRD techniques [36]. Durability studies with metakaolin as a substitute of cement were carried out $[37,38]$. A study concluded that the concrete characteristics have been improved by metakaolin. The study proposed five percent, ten percent, and fifteen percent replacements by weight of cement [39-41]. A study was conducted on the durability of concrete with metakaolin against sulphate attack [42].

1.1. Significance of Research. Concrete is globally consumed in large quantities in construction. Cement, the principal ingredient of concrete, needs substantial amounts of energy to manufacture and it releases large amounts of carbon dioxide, which has detrimental environmental effects. Therefore, research involving supplementary cementing materials has continuously proven the benefits of incorporating cement replacement materials. In furtherance to this research domain, in this study, naturally occurring zeolite and kaolin (used as metakaolin) have been investigated to arrive at recommended quantities of metakaolin and zeolite as partial replacements of cement.

\section{Experimental Work}

2.1. Raw Materials. Naturally occurring zeolite and kaolin were sourced from the Rajasthan mines in India. Zeolite was put through a filtration process for removal of impurities. Metakaolin was manufactured from kaolin by a burning process similar to cement at a temperature between 600 and $850^{\circ} \mathrm{C}$ in Astrra Chemicals, Chennai, India. Aluminum, silicon, and oxygen make up the majority of natural zeolites. They are aluminosilicates, which belong to the "molecular 
sieves" family of microporous solids. The framework comprises a tetrahedral assemblage of $\mathrm{AlO}_{4}$ and $\mathrm{SiO}_{4}$ linked together in different configurations with oxygen atoms, forming a simple crystal lattice with holes of molecular diameters through which molecules can pass.

Natural zeolite was utilized in a $10 \%$ aqueous slurry with a pH of 8.1, bulk density after 100 drops $(\mathrm{g} / \mathrm{cc}$ ) of 0.60 , water absorption of $81.8 \mathrm{G} / 100 \mathrm{~g}$, and specific gravity of 2.1 . Metakaolin used had a $\mathrm{pH}$ (10 percent solids) of 4.5-5.5, bulk density (kg/lit) of $0.4-0.5$, specific surface area $(\mathrm{m} 2 / \mathrm{g})$ of 19-20, and specific gravity of 2.6. The cement was of OPC 53 grade with a specific gravity of 3.15 , normal consistency of $27 \%$, initial setting of 78 minutes, and final setting of 528 minutes. The cement soundness test yielded $2 \mathrm{~mm}$ result.

The chemical composition of OPC 53 grade cement, natural zeolite, and metakaolin is represented in Table 1.

The superplasticizer was a polycarboxylic ether-based liquid with a pH of about 6.0 , a volumetric mass of $1.09 \mathrm{~kg} /$ liter at $200 \mathrm{C}$, and an alkali content of less than $1.5 \mathrm{~g} \mathrm{Na}_{2} \mathrm{O}$ equivalent/liter of admixture. Concrete was made with fine aggregates ( $\mathrm{M}$ sand) that passed through a $4.75 \mathrm{~mm}$ IS sieve and coarse aggregates that passed through a $20 \mathrm{~mm}$ sieve. Water with a $\mathrm{pH}$ of 7 was utilized.

2.1.1. Scanning Electron Microscopy (SEM) of Natural Zeolite and Metakaolin. Figure 1 shows the scanning electron microscopy (SEM) of natural zeolite. SEM was performed mainly to understand the morphology of the system. The heterogeneous nature of the surface was well evidenced by the micrograph. The surface exhibited a shapeless, rod-like, and spherical structure with a high degree of aggregation. The system showed the presence of voids in the natural zeolite.

Figure 2 shows the scanning electron microscopy (SEM) of metakaolin. The surface exhibited more voids having mostly elongated rod-like structures with fewer independent particles and grains. Some were shapeless, and others were in spherical form. The processing conditions might have driven the crystal growth mainly towards a rodlike morphology.

2.1.2. XRD Analysis of Natural Zeolite and Metakaolin. $\mathrm{X}$-ray diffraction analysis is a material science technique for determining the crystallographic structure of a material.

Figure 3 shows the XRD graph for natural zeolite. The XRD pattern revealed the presence of crystalline compounds in the final system. Sharp and intense peaks with low full width at half maximum unambiguously confirmed the presence of crystallites with large sizes. Some compounds were not observed and some were observed with less intensity which might be due to their low concentration or due to their amorphous nature. The less exposure of miller planes due to the complexity of the system might be another reason for the absence of peaks corresponding to certain compounds in the pattern. The major compounds found were quartz alumina and calcium oxide with minor quantities of titania, ferrite, and magnesium oxide. The peaks at $2 \theta$ values around $23^{\circ}, 27^{\circ}, 30^{\circ}, 37^{\circ}$, and $40^{\circ}$ were indexed to the quartz structure.
TABLE 1: The chemical properties of OPC 53 grade cement, natural zeolite, and metakaolin.

\begin{tabular}{lccc}
\hline Constituents (\%) & \multicolumn{3}{c}{ Materials } \\
& OPC 53 & Natural zeolite & Metakaolin \\
\hline $\mathrm{SiO}_{2}$ & 21.25 & 74.3 & 52 \\
$\mathrm{Al}_{2} \mathrm{O}_{3}$ & 4.33 & 10.52 & 46 \\
$\mathrm{Fe}_{2} \mathrm{O}_{3}$ & 1.85 & 1.6 & 0.6 \\
$\mathrm{TiO}_{2}$ & 0.13 & - & 0.65 \\
$\mathrm{CaO}$ & 64.3 & 4.25 & 0.09 \\
$\mathrm{MgO}$ & 1.81 & 0.6 & 0.3 \\
$\mathrm{Na} \mathrm{K}_{2} \mathrm{O}$ & 0.17 & - & 0.1 \\
$\mathrm{~K}_{2} \mathrm{O}$ & 0.71 & - & 0.03 \\
$\mathrm{LOI}$ & 1.5 & 5.3 & 1 \\
\hline
\end{tabular}

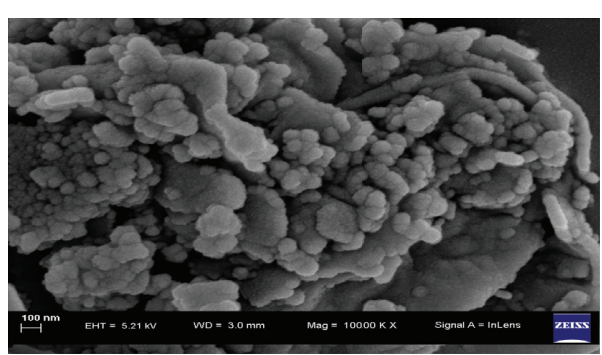

FIgURE 1: Scanning electron microscopy (SEM) of natural zeolite.

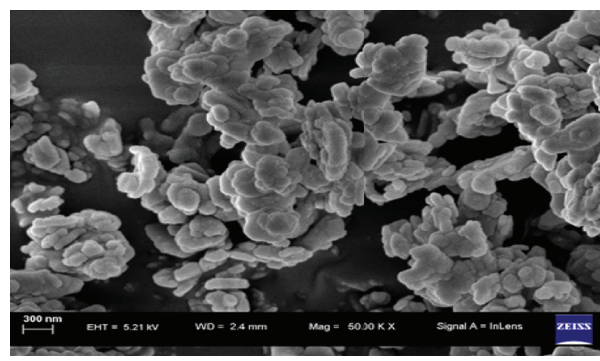

Figure 2: Scanning electron microscopy (SEM) of metakaolin.

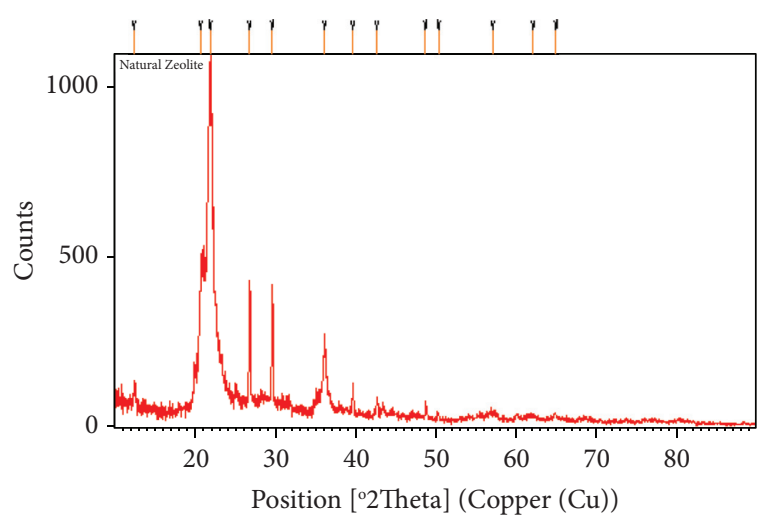

FIGURE 3: Natural zeolite XRD graph.

Figure 4 shows the XRD graph for metakaolin. The sharp peak points refer to the presence of kaolinite, and in $2 \theta$, the lower peak points refer to the presence of quartz. The sharp 


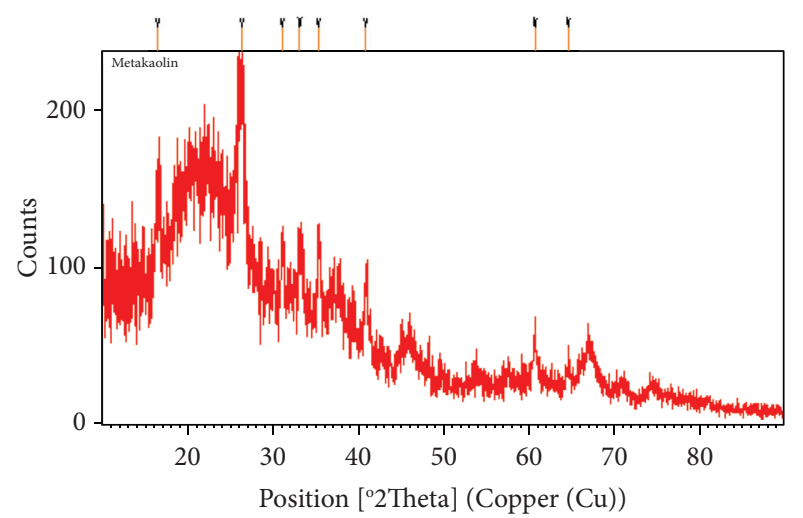

FIGURE 4: Metakaolin XRD graph.

peaks at $2 \theta$ values around $18^{\circ}, 25^{\circ}, 28^{\circ}, 32^{\circ}, 34^{\circ}, 36^{\circ}$, and $41^{\circ}$ were indexed to the calcium oxide.

2.2. Test Methods. Table 2 shows the mix design details of mixes computed according to IS 10262-2019. The raw ingredients were weighed in a computerized balance and batched according to the optimal mix percentage. The raw materials such as fine aggregate, coarse aggregate, cement, natural zeolite, and metakaolin were measured and adequately mixed. A superplasticizer solution dissolved in water was then added to the mixture until it became homogeneous. Extreme caution was taken to avoid concrete bleeding and segregation. The sample preparation was completed by using a pan mixer.

2.3. Slump Test (IS 456-2000). A slump test was performed according to IS 456-2000 to assess the workability of fresh concrete.

2.4. Preparation of Concrete Specimen. The pan mixer was used to mix concrete with a variety of different components. The inside surfaces of the chosen mould were lubricated. The produced homogeneous concrete mixture was put into the mould and compacted to prepare the necessary sized specimen. The concrete specimen was left in the mould for 24 hours until it hardened, after which it was cured at room temperature.

2.5. Compressive Strength. The concrete compressive strength test was carried out following IS 515-1959. Observations and results were recorded for 3, 7, 28, 60, and 90 days cured specimens.

Compressive strength $=($ maximum load $/$ net area of concrete cube) $\mathrm{MPa}$.

2.6. Split Tensile Strength. IS 515-1959 was used to conduct a split tensile strength test on concrete. Observations and results were recorded for $3,7,28,60$, and 90 days cured specimens.

Split tensile strength $=(2 \mathrm{P} / \pi \mathrm{DL}) \mathrm{MPa}$.
TABLE 2: Mix design of concrete.

\begin{tabular}{lccc}
\hline Designation & Cement \% & Natural zeolite $\%$ & Metakaolin \% \\
\hline Mix 1 & 95 & 5 & 0 \\
Mix 2 & 90 & 5 & 5 \\
Mix 3 & 85 & 5 & 10 \\
Mix 4 & 80 & 5 & 15 \\
\hline
\end{tabular}

2.7. Flexure Strength. The concrete beam of size $100 \times 100 \times 500 \mathrm{~mm}$ was symmetrically supported by two parallel steel rollers at a distance of $40 \mathrm{~cm}$ from the centers of the two rollers. The load was applied through two rollers mounted at $1 / 3$ rd of the supporting span. The load on concrete was applied without shock, and the load was increased continuously at a rate of $0.06+0.04 \mathrm{~N} / \mathrm{mm}^{2}$ per second. The flexural strength was expressed as the modulus of rupture as per the IS 515-1959. Observations and results were recorded for $3,7,28,60$, and 90 days cured specimens.

Flexure strength $=(\mathrm{PL} / \mathrm{bd} 2) \mathrm{MPa}$.

\section{Result and Analysis}

3.1. Slump Test. From Figure 5, it was observed that the slump values for fresh concrete mixed with natural zeolite and metakaolin were in the range of $43 \mathrm{~mm}$ to $48 \mathrm{~mm}$. Mix 3 had attained the maximum slump value of $48 \mathrm{~mm}$.

3.2. Compressive Strength Test. From Figure 6, it was been observed that the compressive strength values for hardened concrete for different mixes for $3,7,28,60$, and 90 days were in the range of $30 \mathrm{MPa}$ to $72 \mathrm{MPa}$. At 90 days, mix $3 \mathrm{had}$ attained the maximum compressive strength value of $72 \mathrm{MPa}$.

3.3. Split Tensile Strength Test. From Figure 7, it was observed that the split tensile strength values for hardened concrete for the different mixes for $3,7,28,60$, and 90 days were in the range of $3.1 \mathrm{MPa}$ to $5.3 \mathrm{MPa}$. At 90 days, mix 3 had attained the maximum split tensile strength value of $5.3 \mathrm{MPa}$.

3.4. Flexural Strength Test. From Figure 8, it was observed that the flexural strength values for hardened concrete for different mixes for $3,7,28,60$, and 90 days were in the range of $4.03 \mathrm{MPa}$ to $9.44 \mathrm{MPa}$. At 90 days, mix $3 \mathrm{had}$ attained the maximum split tensile strength value of $9.44 \mathrm{MPa}$.

\subsection{Mechanism Analysis}

3.5.1. XRD Analysis. In this research, mix 2 and mix 4 were prepared considering metakaolin concentration extremities (5\% and 15\%) while keeping the natural zeolite concentration constant. Concrete cubes of size $150 \mathrm{~mm} * 150 \mathrm{~mm} * 150 \mathrm{~mm}$ for the two mixes were prepared and cured for 28 days, and then the cubes were finely ground. The study of XRD was performed on the ground material which had passed through a 90-micron sieve. 


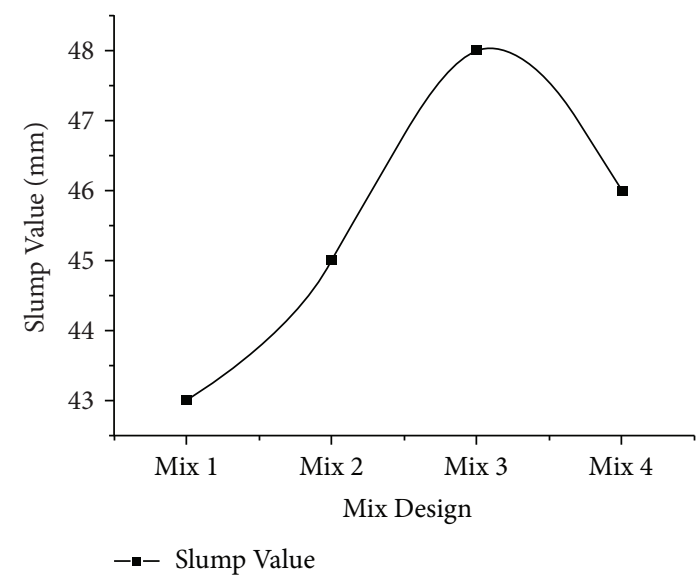

FIgURE 5: Graph of slump value for different mixes.

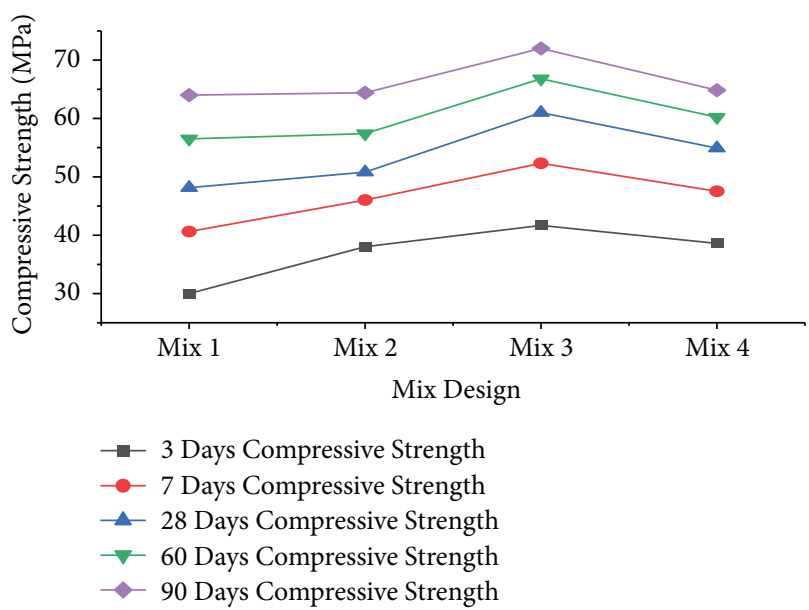

FIGURE 6: Graph of compressive strength for different mixes.

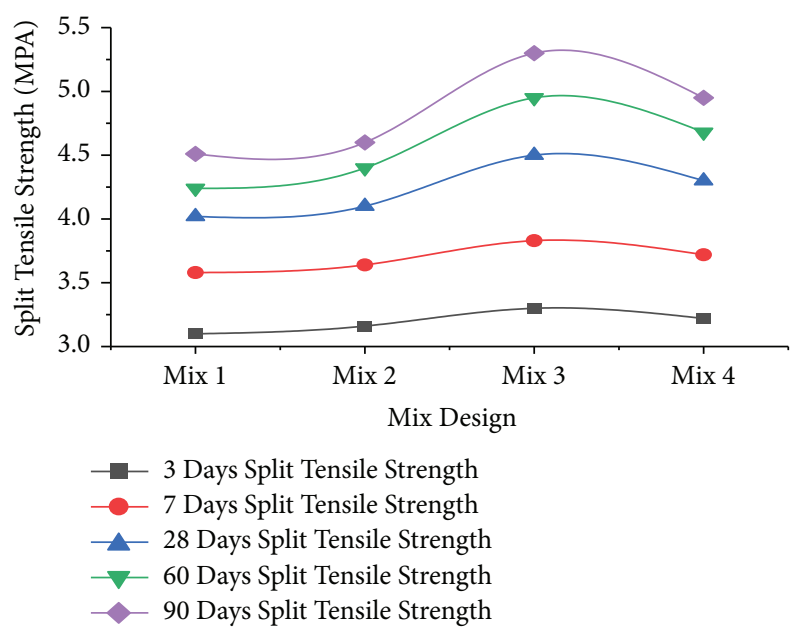

FIGURE 7: Graph of tensile strength for different mixes.

Figure 9 refers to the XRD graph of mix 2. The results were well in agreement with the XRF results. The peak at $2 \theta=13^{\circ}$ was attributed to kaolinite. Metakaolin was not observed in the pattern due to its amorphous nature. The

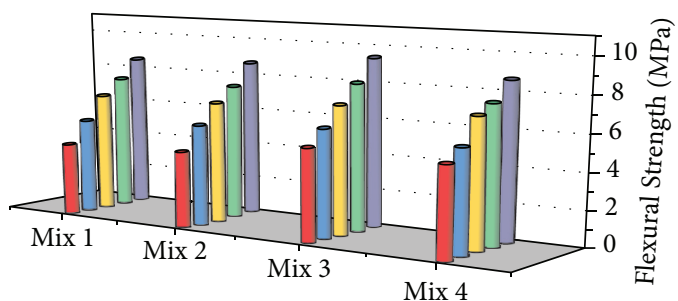

$$
\begin{aligned}
& \square \\
& \square \text { Days Flexural Strength } \\
& 7 \text { Days Flexural Strength } \\
& \square \text { 28 Days Flexural Strength } \\
& \square 60 \text { Days Flexural Strength } \\
& \square 90 \text { Days Flexural Strength }
\end{aligned}
$$

FIGURE 8: Graph of flexural strength for different mixes.

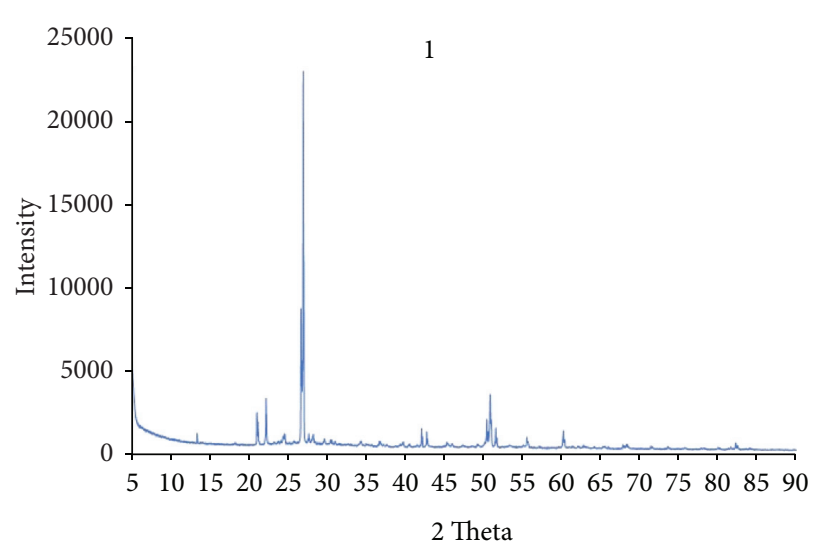

Figure 9: Mix 2 XRD graph.

peaks at $2 \theta$ values around $21^{\circ}, 27^{\circ}, 43^{\circ}, 52^{\circ}$, and $60^{\circ}$ were indexed to the quartz structure. Peaks around $23.4^{\circ}$ and $29.4^{\circ}$ were attributed to gypsum and calcite, respectively [43-45]. The peak corresponding to gypsum was observed to be intense and sharp. A less intense peak at $24^{\circ}$ was indexed to ferrite structure. Peaks at $2 \theta$ values around $28.5^{\circ}$ and $34^{\circ}$ were pointed towards mullite crystal planes.

Figure 10 refers to the XRD graph of mix 4 . In mix 4, the majority of the peaks were found to be sharp and intense, which confirmed the presence of crystalline compounds. Some broad peaks with high full width at the half maximum supported the presence of amorphous compounds. A dominant peak of natural zeolite at $2 \theta$ value around $7^{\circ}$ was observed in the pattern. The peak at $11^{\circ}$ was indexed to the (100) miller planes of gypsum. The peaks at $17^{\circ}, 28^{\circ}$, and $34^{\circ}$ were attributed to the crystal planes corresponding to mullite. A sharp peak with a good signal-to-noise ratio was observed at $2 \theta=21^{\circ}$, which was assigned to the (003) miller plane of muscovite. A peak with fairly good intensity at $29.5^{\circ}$ was indexed to calcite. The peaks around $32^{\circ}, 37.38^{\circ}$, and $64.30^{\circ}$ were assigned to the miller planes of calcium oxide $(\mathrm{CaO})$. Peaks at $27^{\circ}, 43^{\circ}, 46^{\circ}, 55^{\circ}$, and $60^{\circ}$ were attributed to quartz structures [43-46]. 


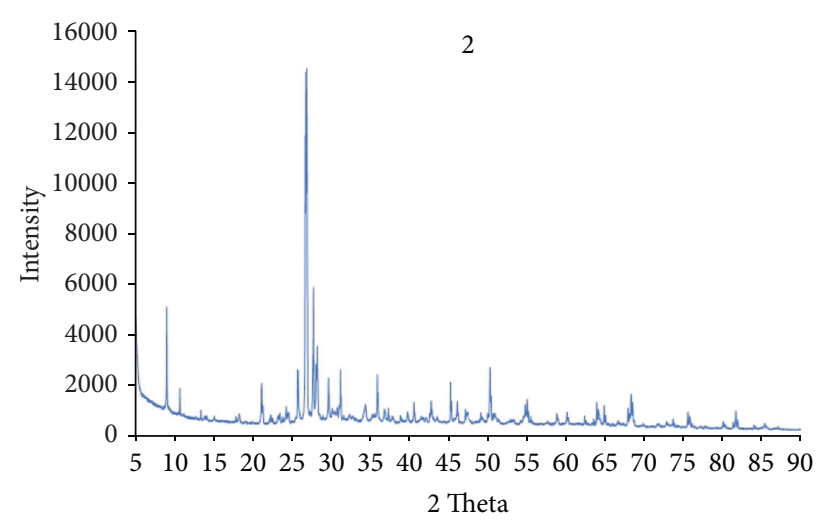

FIGURE 10: Mix 4 XRD graph.

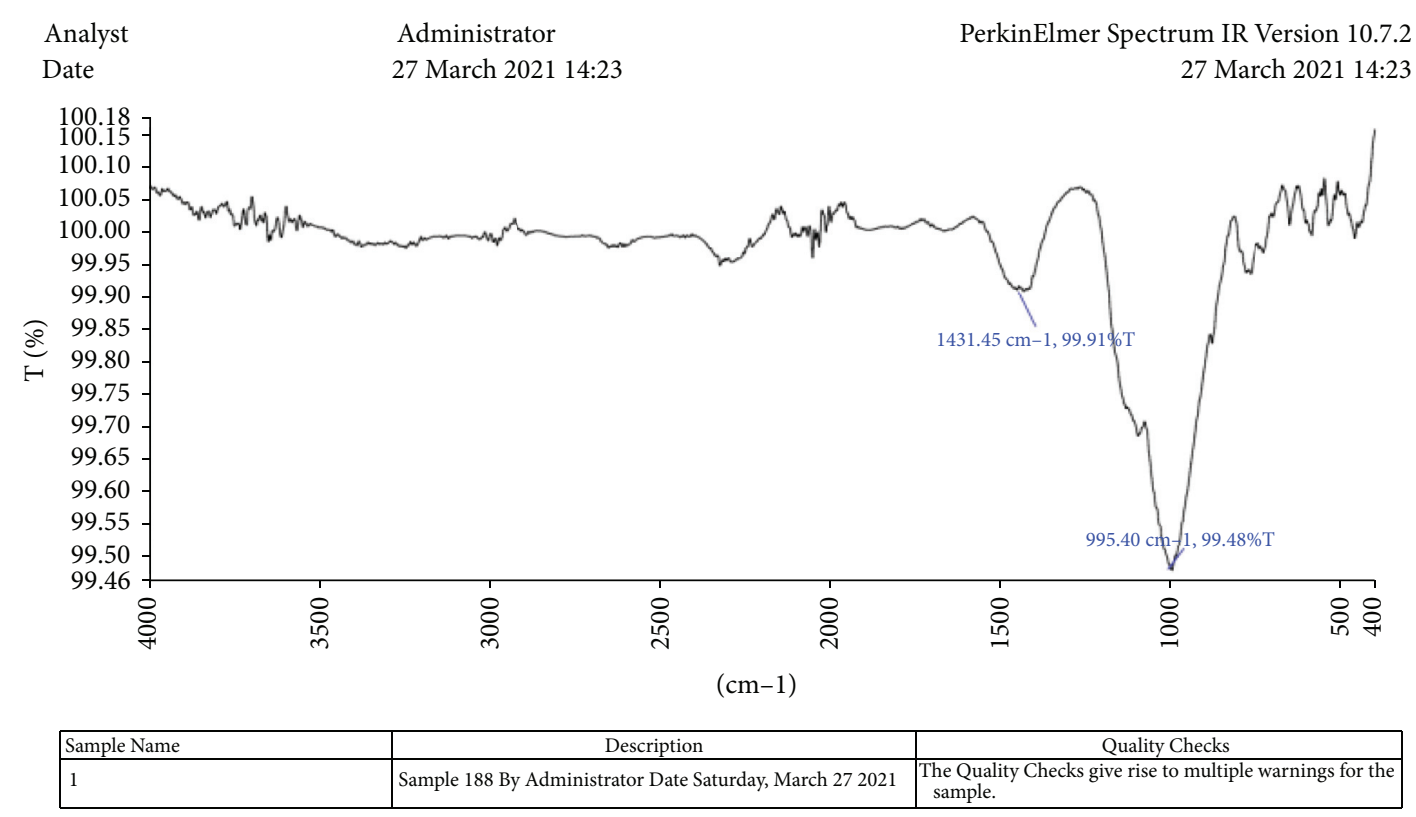

FIgURe 11: Mix 2 FT-IR pattern.

3.5.2. FT-IR Analysis. Figures 11 and 12 refer to FT-IR patterns for mix 2 and mix 4, respectively. FT-IR patterns of both the mixes were more or less the same. The band at $464 \mathrm{~cm}^{-1}$ was attributed to the $\mathrm{O}-\mathrm{Si}$-O bending vibrations $[47,48]$. A band with fairly good intensity at $587 \mathrm{~cm}^{-1}$ was indexed to the vibrations corresponding to the $\mathrm{Si}-\mathrm{O}-\mathrm{Al}$ bond [49]. Another band at $533 \mathrm{~cm}^{-1}$ was due to the vibrations of the $\mathrm{Ca}-\mathrm{O}$ bond [50]. The sharp band at 777 $\mathrm{cm}^{-1}$ was assigned to the symmetric stretching vibrations of the Si-O-Si bond [51]. The strong band at $995 \mathrm{~cm}^{-1}$ supports the existence of aluminum in the octahedral position, which confirms the presence of mullite [52]. A well-resolved band around $1430 \mathrm{~cm}^{-1}$ was pointed towards the $\mathrm{C}-\mathrm{O}$ stretching of the carbonate group. The harmonic vibrational mode of $\mathrm{C}-\mathrm{O}$ was observed as a minor band at $2985 \mathrm{~cm}^{-1}$ [50]. Broadband around 3379 $\mathrm{cm}^{-1}$ was assigned to the asymmetric stretching mode of the hydroxyl group of natural zeolite. The results distinctly confirmed the existence of aluminosilicates and calcium compounds in the final system.

3.5.3. Thermogravimetric Analysis (TGA). Figures 13 and 14 refer to thermogravimetric analysis (TGA) of mix 2 and mix 4, respectively. Thermogravimetry was used to study the thermal stability of the prepared systems. Both the mixes exhibited more or less identical decomposition patterns. A minor weight loss observed between $100^{\circ} \mathrm{C}$ to $200^{\circ} \mathrm{C}$ was due to removing adsorbed and lattice-held water. Another significant weight loss between $410^{\circ} \mathrm{C}$ to $420^{\circ} \mathrm{C}$ was attributed to the decomposition of impurities (mainly carbonaceous materials) present in the system. After $420^{\circ} \mathrm{C}$, the compounds were found to be stable up to $800^{\circ} \mathrm{C}$. There were no noticeable weight losses either due to the degradation of compounds or the phase changes in the analysis. The analysis proved the ability of the system 


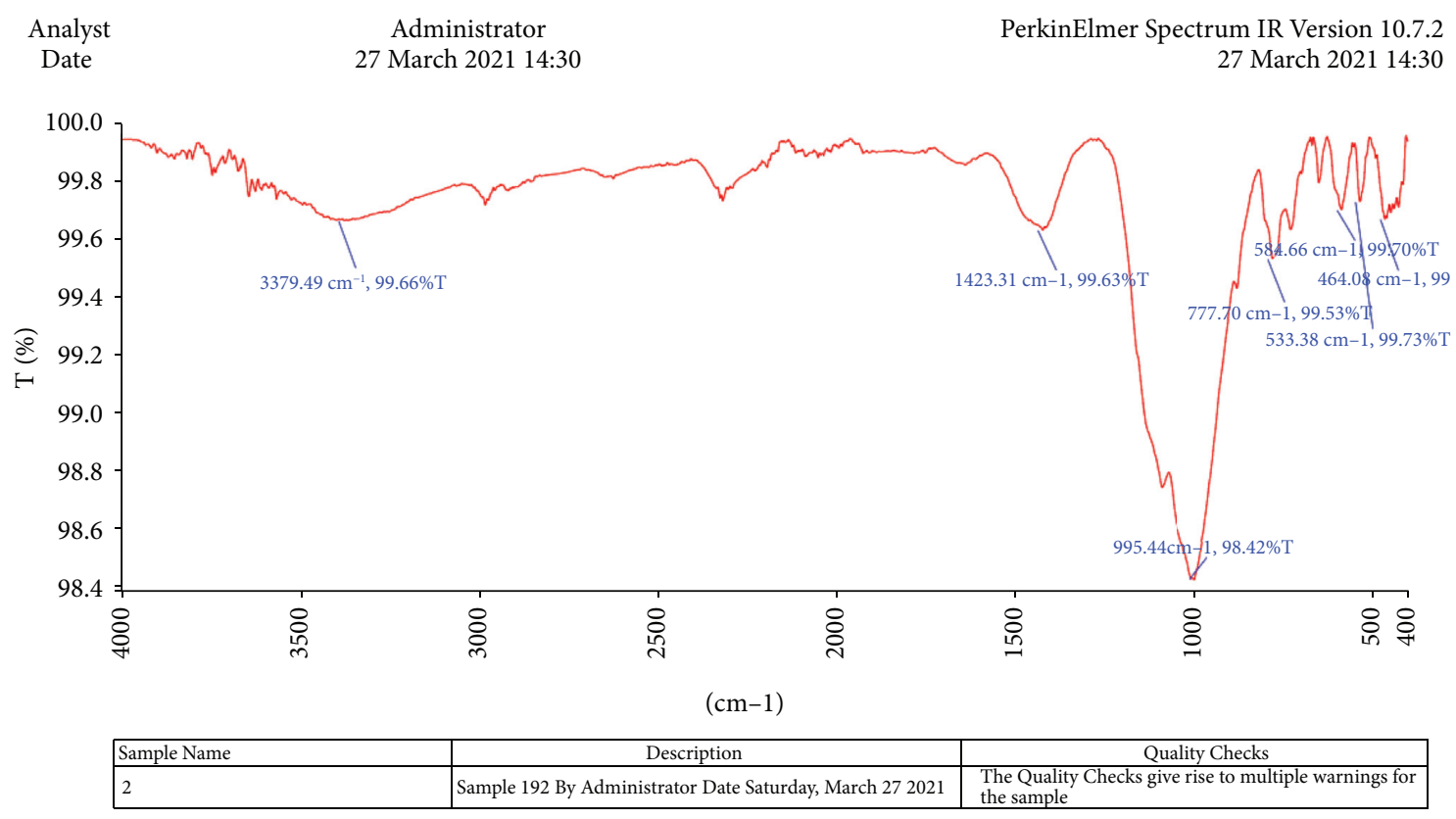

Figure 12: Mix 4 FT-IR pattern.

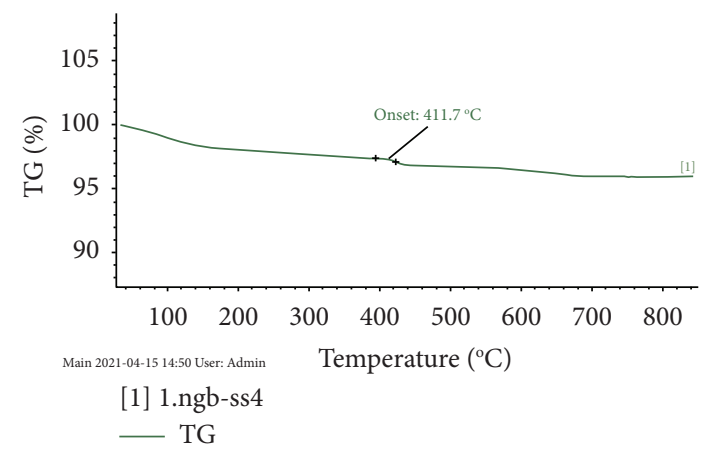

Figure 13: : Mix 2 thermogravimetric analysis (TGA).

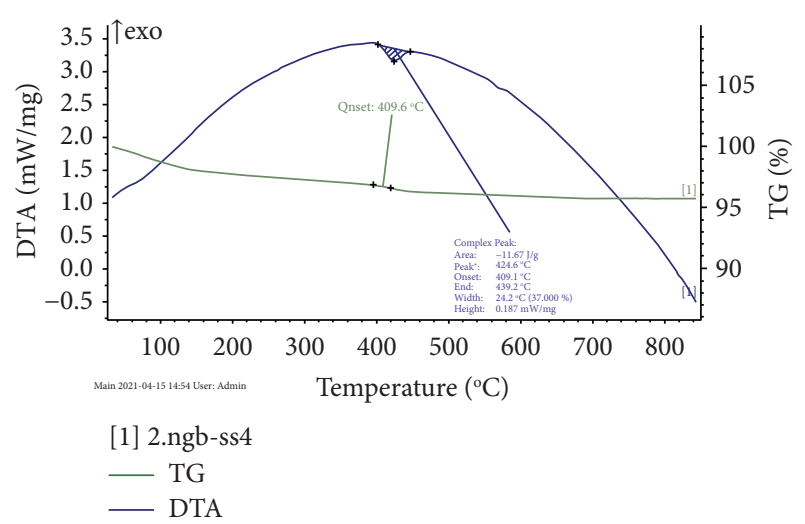

Figure 14: Mix 4 thermogravimetric analysis (TGA).

to withstand high-temperature conditions which might be due to the presence of stable metal oxides to a large extent.

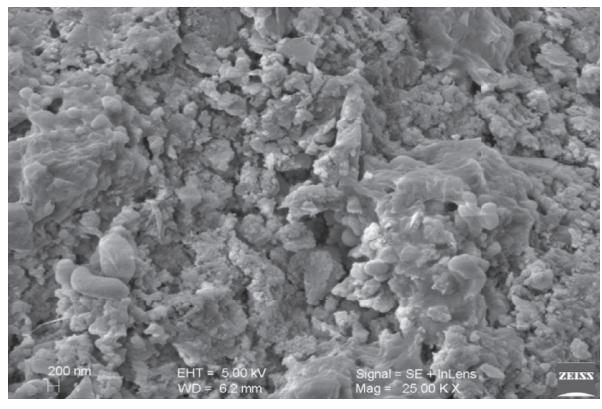

Figure 15: Scanning electron microscopy (SEM) of mix 2.

3.5.4. SEM: Scanning Electron Microscopy. Figure 15 refers to the SEM of mix 2 . The system revealed a slightly porous nature, and the surface exhibited shapeless independent particles with a high degree of aggregation which might be due to the presence of natural zeolite. However, the pore distribution followed a nonuniform pattern. The processing conditions might have facilitated the crystal growth towards specific shapes and the aggregation process.

Figure 16 refers to the SEM of mix 4. Micrograph exhibited heterogeneous nature of the surface, which contains shapeless independent particles and rod-like structures with a high degree of aggregation. Due to the high concentration of metakaolin, bulk porosity may have become dominant in the system.

3.5.5. Evidence for the Regression Analysis. Results from the regression model are shown below.

As shown in equations (1) and (2), the single-factor regression model regresses concrete strength on mix combinations and curing days individually. Equation (3) is a 


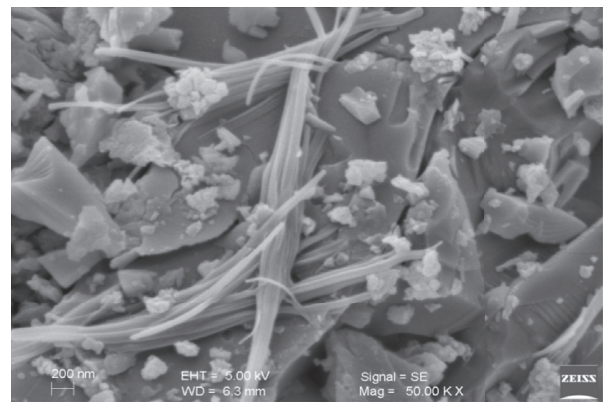

FIGURE 16: Scanning electron microscopy (SEM) of mix 4.

TABLE 3: Linear regression for the strength of concrete for all mix designs for 3, 7, 28, 60, and 90 days for $5 \%$ of natural zeolite with varying percentages of metakaolin.

\begin{tabular}{|c|c|c|c|c|c|c|c|}
\hline Test & Model & $\beta 0$ (constant) & $\beta 1$ (days) & $\beta 2$ (combination) & $R$-squared (\%) & $F$-statistic & $P$ value \\
\hline \multirow{3}{*}{ Compression test } & SFD & $31.33^{* * *}[12.78]$ & $7.17^{* * *}[9.71]$ & NA & 84 & 94.22 & $<0.05$ \\
\hline & SFC & $46.91^{* * *}[7.56]$ & NA & $2.37^{* * *}[1.05]$ & 6 & 1.10 & 0.309 \\
\hline & DFDC & $6.394^{* * *}[9.10]$ & $0.893^{* * *}[11.78]$ & $0.433^{* * *}[3.08]$ & 90 & 74.10 & $<0.05$ \\
\hline \multirow{3}{*}{ Split tensile test } & SFD & $2.855^{* * *}[22.95]$ & $0.416^{* * *}[11.10]$ & NA & 87 & 123.25 & $<0.05$ \\
\hline & SFC & $3.8^{* * *}[10.68]$ & NA & $0.125^{* * *}[0.96]$ & 5 & 0.93 & 0.348 \\
\hline & DFDC & $2.543^{* * *}[18.32]$ & $0.416^{* * *}[13.75]$ & $0.125^{* * *}[3.26]$ & 92 & 99.82 & $<0.05$ \\
\hline \multirow{3}{*}{ Flexural test } & SFD & $3.609^{* * *}[19.15]$ & $1.044^{* * *}[18.38]$ & NA & 95 & 337.75 & $<0.05$ \\
\hline & SFC & $6.273^{* * *}[7.24]$ & NA & $0.188^{* * *}[0.59]$ & 2 & 0.35 & 0.561 \\
\hline & DFDC & $3.14^{* * *}[14.87]$ & $1.044^{* * *}[22.65]$ & $0.188^{* * *}[3.22]$ & 97 & 261.80 & $<0.05$ \\
\hline
\end{tabular}

SFD is the single-factor curing days, SFC is the single-factor concrete mix combination, DFDC is the double factor both curing days and concrete mix combination, ${ }^{* * *}$ indicates significant at 0.05 level, and the parenthesis denotes $t$ statistics ( $\mathrm{t}$-value).

double factor regression model that shows concrete strength as a function of concrete mix combination and curing days taken together.

$$
\begin{gathered}
S_{m}=\beta_{0}+\left(\beta_{1} * C_{t}\right)+\varepsilon_{i}, \\
S_{m}=\beta_{0}+\left(\beta_{2} * D_{t}\right)+\varepsilon_{i}, \\
S_{m}=\beta_{0}+\left(\beta_{1} * C_{t}\right)+\left(\beta_{2} * D_{t}\right)+\varepsilon_{i},
\end{gathered}
$$

where $S_{m}$ is the parameter referring to the strength of concrete, $\beta_{0} s$ is the coefficient constant, $\beta_{1}$ is the coefficient for concrete $\operatorname{mix}, \beta_{2}$ is the coefficient of curing duration, $\mathrm{Ct}$ is the combination of mineral admixtures in concrete (i.e., mixes), Dt is the curing days, and $\varepsilon_{i}$ is the standard error.

Concrete mix combinations and curing days are the independent variables in the models. Concrete strength is the dependent variable. The intercepts $\left(\beta_{0}\right)$ are found larger in the single-factor model suggesting that the model does not adequately explain the strong link between the independent variables. This possibly might be a result of errors in parameters like the water-cement ratio.

According to the results of SPSS software for the differential equations describing concrete strength for single factor (curing days or concrete mix combination) and double factors (both curing days and concrete mix combination), equation (2) has the highest $R$ square value. This shows a significantly stronger link among concrete strength, the number of curing days, and the concrete mix. The analysis obtained is shown in Table 3.

\section{Discussion}

The use of natural zeolite and metakaolin in concrete manufacturing can help to promote sustainable and environmentally friendly building practices without sacrificing strength. The use of a carboxylate ether-based superplasticizer as an admixture can contribute to improved workability. Mineral admixtures can reduce $\mathrm{CO} 2$ emissions when cement is partially replaced. The recent findings demonstrate that employing mineral admixtures like natural zeolite and metakaolin to make eco-friendly concrete is a step forward in the sustainable building strategy.

\section{Conclusions}

This study arrived at the following conclusions:

(i) The optimum concrete mix is mix 3 which contains 85 percent cement, $5 \%$ natural zeolite, and $10 \%$ metakaolin. The mix achieved the highest compressive strength of $64.58 \mathrm{MPa}$ after 28 days of curing and $72 \mathrm{MPa}$ after 90 days of curing, thus indicating that it is a high-strength concrete.

(ii) Mix 3 had the most significant split tensile strength of $4.95 \mathrm{MPa}$ after 28 days and $5.3 \mathrm{MPa}$ after 90 days of curing. The maximum flexural strength was 
8.56 MPa after 28 days of curing and 9.44 MPa after 90 days of curing for the same mix.

(iii) The existence of calcium oxide, quartz, gypsum, and small amounts of titania, ferrite, and magnesium oxide was verified by XRD analysis. These have assisted in the improvement of pozzolanic binding and strength. TGA analysis results are consistent with XRD analysis results in which the former has indicated that the presence of metal oxides in substantial amounts in concrete has aided in the improvement of mechanical characteristics.

(iv) Aluminosilicates and calcium compounds were observed in concrete using FT-IR. They have assisted in the development of concrete strength and improved performance. SEM has exposed the presence of rod-like structures and shapeless independent particles of metakaolin and natural zeolite. This has made the paste structure more complex and has increased the voids and the bulk porosity. Therefore, higher percentages of metakaolin are likely to affect the strength of concrete adversely.

(v) The $R$ square value in the double factor model can be regarded as an excellent way to estimate concrete strength.

\section{Data Availability}

All the data, models, or analyzed during the study are included in this published article.

\section{Conflicts of Interest}

The authors declare that there are no conflicts of interest regarding the publication of this paper.

\section{References}

[1] M. Ashik and D. Gomathi, "Strength properties of concrete using metakaolin," International Journal of Engineering Research, vol. 6, no. 11, 2017.

[2] A. T. Bakera and M. G. Alexander, "Use of Metakaolin as Supplementary Cementitious Material in Concrete," with Focus on Durability Properties." RILEM Technical Letters, vol. 4, pp. 89-102, 2019.

[3] S. Samad and A. Shah, "Comparative analysis of flexural strength and modulus elasticity of sustainable concrete using supplementary cementitious material (scm)," Preprints, 2020.

[4] L. Turanli, B. Uzal, and F. Bektas, "Effect of large amounts of natural pozzolan addition on properties of blended cements," Cement and Concrete Research, vol. 35, no. 6, pp. 1106-1111, 2005.

[5] E. Vejmelková, K. Dana, and T. Kulovaná, "Engineering properties of concrete containing natural zeolite as supplementary cementitious material: strength, toughness, durability, and hygrothermal performance," Cement and Concrete Composites, vol. 55, pp. 259-267, 2015.

[6] E. Vejmelková, T. Kulovaná, M. Keppert, M. Ondráček, and R. Černý, "Natural zeolite as environmentally friendly supplementary cementitious material in concrete," Eco-Architecture $I V$, vol. 165, 2012.
[7] H. Zhu, G. Liang, Z. Zhang, Q. Wu, and J. Du, "Partial replacement of metakaolin with thermally treated rice husk ash in metakaolin-based geopolymer," Construction and Building Materials, vol. 221, pp. 527-538, 2019.

[8] C. Sgarlata, A. Formia, F. Ferrari, and C. Leonelli, "Effect of the introduction of reactive fillers and metakaolin in waste clay-based materials for geopolymerization processes," Molecules, vol. 26, no. 5, 2021.

[9] A. B. Shaik and H. R. Kommineni, "Experimental investigation on strength and durability properties of concrete using bauxite residue and metakaolin," Materials Today: Proceedings, vol. 33, pp. 583-586, 2020.

[10] B. B. Raggiotti, B. Belén, M. J. Positieri, F. Locati, J. A. Murra, and S. Marfil, "Zeolite, Study of Aptitude as a Natural Pozzolan Applied to Structural Concrete," Revista de La Construcción, vol. 14, no. 2, pp. 14-20, 2015.

[11] B. B. Raggiotti, B Belén, M. J. Positieri, and Á. Oshiro, "Natural Zeolite, a Pozzolan for Structural Concrete," Procedia Structural Integrity, vol. 11, pp. 36-43, 2018.

[12] S. N. Manu and P. Dinakar, "Fresh and mechanical properties of high strength self compacting concrete using metakaolin," RILEM Bookseries, vol. 10, pp. 509-515, 2015.

[13] N. A. M. Nasir and M. J. McCarthy, "Effect of Metakaolin on Early Strength of GGBS Ternary Concrete," Applied Mechanics and Materials, vol. 584-586, pp. 1551-1557, 2014.

[14] J. Zhang, X. Ding, Q. Wang, and X. Zheng, "High-strength concrete mixture with calcined zeolite particles for shrinkage reduction," Magazine of Concrete Research, ICE Publishing, vol. 71, no. 13, , pp. 690-699, Londan, UK, 2019.

[15] Z. Yu, W. Yang, P. Zhan, and X. Liu, "Strengths, microstructure and nanomechanical properties of concrete containing high volume of zeolite powder," Materials, vol. 13, no. $18,2020$.

[16] N. C. Thang, N. V. Tuan, K. H. Yang, and Q. T. Phung, "Effect of zeolite on shrinkage and crack resistance of high-performance cement-based concrete," Materials, vol. 13, no. 17, 2020.

[17] P. M. Zadeh, S. F. Saghravani, and G. Asadollahfardi, "Mechanical and Durability Properties of Concrete Containing Zeolite Mixed with Meta-kaolin and Micro-nano Bubbles of Water," Structural Concrete, vol. 20, no. 1, 2019.

[18] M. J. Shannag, "High strength concrete containing natural pozzolan and silica fume," Cement and Concrete Composites, vol. 22, no. 6, pp. 399-406, 2000.

[19] A. K. Al-Shamiri, A. Khalil, J. H. Kim, T. F. Yuan, and Y. S. Yoon, "Modeling the compressive strength of highstrength concrete: an extreme learning approach," Construction and Building Materials, vol. 203, pp. 204-219, 2019.

[20] M. Hajforoush, R. Madandoust, and M. Kazemi, "Effects of simultaneous utilization of natural zeolite and magnetic water on engineering properties of self-compacting concrete," Asian Journal of Civil Engineering, vol. 20, no. 2, pp. 277-283, 2019.

[21] B. D. Ikotun and S. Ekolu, "Strength and durability effect of modified zeolite additive on concrete properties," Construction and Building Materials, vol. 24, no. 5, pp. 749-757, 2010.

[22] G. Asadollahfardi, B. Yahyaei, A. M. Salehi, and A. Ovesi, "Effect of Admixtures and Supplementary Cementitious Material on Mechanical Properties and Durability of Concrete," Civil Engineering Design, vol. 2, no. 1-2, 2020.

[23] D. Nagrockiene and G. Girskas, "Research into the properties of concrete modified with natural zeolite addition," Construction and Building Materials, vol. 113, pp. 964-969, 2016. 
[24] E. Vejmelková, K. Dana, M. Čáchová, M. Keppert, H. Adam, and R. Černý, "Application of Zeolite as a Partial Replacement of Cement in Concrete Production," Applied Mechanics and Materials, vol. 621, pp. 30-34, 2014.

[25] V. Kočí, M. Jerman, J. Maděra, and R. Černý, "Effect of zeolite admixture on freeze/thaw resistance of concrete exposed to the dynamic climatic conditions," Advanced Materials Research, vol. 982, 2014.

[26] Z. Hashim and R. Hamid, "Effect of metakaolin on the strength and pore size distribution of concrete," Materials Science Forum, vol. 803, pp. 222-227, 2014.

[27] S. Supit, R. Rumbayan, and A. Ticoalu, "Influence of ultrafine metakaolin in improving the compressive strength and durability properties of concrete," Advances in Civil Engineering Materials, 2021.

[28] P. Dinakar, P. K. Sahoo, and G. Sriram, "Effect of metakaolin content on the properties of high strength concrete," International Journal of Concrete Structures and Materials, vol. 7, no. 3, pp. 215-223, 2013.

[29] G. Girskas, G. Skripkiūnas, G. Šahmenko, and A. Korjakins, "Durability of concrete containing synthetic zeolite from aluminum fluoride production waste as a supplementary cementitious material," Construction and Building Materials, vol. 117, pp. 99-106, 2016.

[30] B. Ahmadi and M. Shekarchi, "Use of natural zeolite as a supplementary cementitious material," Cement and Concrete Composites, vol. 32, no. 2, pp. 134-141, 2010.

[31] R. Kumar, N. Shafiq, A. Kumar, and A. A. Jhatial, "Investigating embodied carbon, mechanical properties, and durability of high-performance concrete using ternary and quaternary blends of metakaolin, nano-silica, and fly ash," Environmental Science and Pollution Research International, vol. 28, no. 35, Article ID 49074, 2021.

[32] E. Badogiannis, G. Kakali, and S. Tsivilis, "Metakaolin as supplementary cementitious material," Journal of Thermal Analysis and Calorimetry, vol. 81, no. 2, pp. 457-462, 2005.

[33] A. O. Richard, "Properties of blended metakaolin and glass sludge waste as binder in concrete," in Proceedings of the ICRP 2019 - 4th International Conference on Rebuilding Place, Penang, Malasiya, November 2019.

[34] V. B. V. B. Shikhare and V. B. V. S. Shikhare, "Combine effect of metakaolin, fly ash and steel fiber on mechanical properties of high strength concrete," IOSR Journal of Mechanical and Civil Engineering, vol. 7, no. 1, pp. 01-04, 2013, https://doi.org/ 10.9790/1684-0710104.

[35] K. Shuldyakov, L. Kramar, B. Trofimov, and I. Ivanov, "Superplasticizer Effect on Cement Paste Structure and Concrete Freeze-Thaw Resistance," Advanced Materials in Techology and Building.vol. 1698, no. 1, Article ID 070011, 2016.

[36] H. S. Kim, S. H. Lee, and H. Y. Moon, "Strength Properties and Durability Aspects of High Strength Concrete Using Korean Metakaolin," Construction and Building Materials, vol. 21, no. 6, pp. 1229-1237, 2007.

[37] L. A. Aday, "Effects of reactivity metakaolin on properties of high strength concrete," International Journal of Engineering \& Technology, vol. 7, no. 4, 2018.

[38] M. N. Al-Akhras, "Durability of metakaolin concrete to sulfate attack," Cement and Concrete Research.vol. 36, no. 9, pp. 1727-1734, 2006.

[39] J. M. Khatib and R. M. Clay, "Absorption characteristics of metakaolin concrete," Cement and Concrete Research, vol. 34, no. 1, pp. 19-29, 2004.
[40] M. Frías, M. I. S. D. Rojas, and J. Cabrera, "The effect that the pozzolanic reaction of metakaolin has on the heat evolution in metakaolin-cement mortars," Cement and Concrete Research, vol. 30, no. 2, pp. 209-216, 2000.

[41] W. Sha and G. B. Pereira, "Differential scanning calorimetry study of ordinary Portland cement paste containing metakaolin and theoretical approach of metakaolin activity," Cement and Concrete Composites, vol. 23, no. 6, pp. 455-461, 2001.

[42] J. M. Khatib and S. Wild, "Sulphate resistance of metakaolin mortar," Cement and Concrete Research, vol. 28, no. 1, pp. 83-92, 1998.

[43] P. E. Stutzman, J. W. Bullard, and F. Pan, "Phase Analysis of Portland Cement by Combined Quantitative X-Ray Powder Diffraction and Scanning Electron Microscopy," Journal of Research of the National Institute of Standards and Technology, vol. 121, no. 4, pp. 1-61, 2016.

[44] M. Gougazeh and J. C. Buhl, "Synthesis and Characterization of Zeolite A by Hydrothermal Transformation of Natural Jordanian Kaolin," Journal of the Association of Arab Universities for Basic and Applied Sciences, vol. 15, pp. 35-42, 2014.

[45] P. P. Nampi, P. Moothetty, F. J. Berry, M. Mortimer, and G. W. Krishna, "Aluminosilicates with varying alumina-silica ratios: synthesis via a hybrid sol-gel route and structural characterisation," Dalton Transactions, vol. 39, no. 21, pp. 5101-5107, 2010.

[46] A. Linggawati, "Preparation and characterization of calcium oxide heterogeneous catalyst derived from anadara granosa shell for biodiesel synthesis," in Proceedings of the KnE Engineering Conference on Science and Engineering for Instrumentation, Environment and Renewable Energy, pp. 1-8https://doi.org/10.18502/keg.v1i1.494, UNRI Pekanbaru, Indonesia, September 2016.

[47] J. B. Zhang, S. P. Li, H. Q. Li, and M. M. He, "Acid activation for pre-desilicated high-alumina fly ash," Fuel Processing Technology, vol. 151, pp. 64-71, 2016.

[48] Y. Liu, F. Zeng, B. Sun, P. Jia, and T. Ian, "Structural characterizations of aluminosilicates in two types of fly ash samples from shanxi province, north China," Minerals, vol. 9, no. 6, 2019.

[49] S. Mukherjee and S. K. Srivastava, "Minerals Transformations in Northeastern Region Coals of India on Heat Treatment," Energy \& Fuels, vol. 20, no. 3, 2006.

[50] M. R. Galván, J. Hernández, L. Baños, M. J. Noriega, E. Mario, and G. Rodríguez, Characterization of calcium carbonate, calcium oxide, and calcium hydroxide as starting point to the improvement of lime for their use in construction," Journal of Materials in Civil Engineering, vol. 21, no. 11, pp. 625-708, 2009.

[51] A. Hahn, H. Vogel, S. Andó et al., "Using fourier transform infrared spectroscopy to determine mineral phases in sediments," Sedimentary Geology, vol. 371, no. 1, pp. 27-35, 2018.

[52] A. J. Fernández and A. Palomo, "Mid-Infrared Spectroscopic Studies of Alkali-Activated Fly Ash Structure," Microporous and Mesoporous Materials, vol. 86, no. 1-3, pp. 207-214, 2005. 